\title{
Influence of Word of Mouse and Consumers Attitudes on Consumers' Decision-Making in E-Commerce*
}

\author{
Chen GUO' ${ }^{1}$, Hyunsu KIM², Woohyoung KIM ${ }^{3}$
}

Received: June 26, 2020. Revised: July 02, 2020. Accepted: August 05, 2020.

\begin{abstract}
Purpose: Prior studies rarely investigated the effects of the Word of Mouse (WoM) information on consumers' motivation and willingness to purchase a product. Furthermore, few scholars have studied how word-of-mouth information works and they fail to find consistent results. Research design, data and methodology: This study uses a multivariate regression model to investigate the influence of WoM on consumer attitudes and consumer decision-making. It categorizes the quality of WoM into source level and acceptance level, to analyze its influence from a new perspective. A total of 400 surveys were completed, resulting in 336 usable questionnaires for analysis. It was collected in 14 cities from all regions in China. This study constructs a theoretical model of WoM influence on consumers' purchase willingness based on a systematic review of the related literature on WoM quality, perceived value, customer trust, and consumers' purchase willingness. Results: Empirical results reveal that the Internet WoM (consumer's source level and acceptance level) indirectly affects consumer behavior by influencing consumer attitudes. Conclusions: This study provides practical significance and value for merchants to develop better WoM marketing and to establish the reliability of WoM websites. Companies should consider online WoM from the perspective of consumers, thereby improving existing marketing strategies.
\end{abstract}

Keywords : Word of Mouse, Consumer Attitude, Consumer Decision-Making, Multi-Variable Regression Analysis

JEL Classification Code : L10, L31, L81

\section{Introduction}

The With the enhancement of informationalization and the Internet, more people tend to find information about

* This research is a revision, with supplements, of the content of "An Empirical Study of Influence of Word of Mouse and Consumer Attitudes on Consumers' Decision-Makin in Ecommerce Platform".

1 First Author. Ph.D. student, Department of international trade \& business, Konkuk University, Republic of Korea.

Email: guochen011094@163.com

2 Corresponding Author. Visiting Professor, The Graduate School of Technology Management, Kyunghee University, Republic of Korea. Email: kimnchina@khu.ac.kr

3 Assistant Professor, The Graduate School of Technology Management, Kyunghee University, Republic of Korea. Email: kimwh@khu.ac.kr

(C) Copyright: The Author(s)

This is an Open Access article distributed under the terms of the Creative Commons Attribution Non-Commercial License (https://creativecommons.org/licenses/by-nc/4.0/) which permits unrestricted non-commercial use, distribution, and reproduction in any medium, provided the original work is properly cited. products or services through the Internet. Customers have left a vast number of personal evaluations and records about products in the process of selection. The word of mouse information has become numerous (Zhang, 2011). On the other hand, other consumers have a persuasive reference basis when purchasing products. Moreover, once people leave the word of mouse information on the Internet, it spreads rapidly.

Some marketers have noticed the considerable impact of word of mouse communication, and the product information has been published in the portal or online community through intelligent packaging and planning and has achieved significant economic benefits (Meng, 2017). The following are the main questions discussed in this research: What are the types of word of mouse information, and what factors will affect consumers' attitudes and expansion of information? What is the communication mechanism of the word of mouse? How does it affect consumer decisions? Before conducting specific research, we first introduce the research background and research objects of this paper and 
put forward the core issues of this paper from both theoretical and practical aspects. Then, we further point out the practical and theoretical significance of this research. Finally, based on the above, the innovation of this research is put forward.

The Internet has become an indispensable part of contemporary life. According to the International Telecommunication Union's 2017 statistics report, about $48 \%$ of the world's population used the Internet by the end of 2017, which means that Internet penetration has doubled in the past decade. Based on the 42nd "Statistical Report on the Development of China's Internet Network," released by China Internet Information Center, as of June 2018, the number of Chinese netizens reached 802 million, and the Internet penetration rate reached $57.7 \%$. With the rapid development of the Internet and online technology as other industries, the retail industry has become more convenient and efficient. According to statistics from the National Bureau of Statistics of China, China's online retail sales in the year 2018 were 906.5 billion RMB, an increase of $23.9 \%$ from last year, but this only accounted for about $19 \%$ of the country's total retail sales. We could forecast that the online shopping market still has enormous space to improve. With the maturity and broad application of Web 2.0 technology, more social media sites have sprung up. These social media sites make the online environment easier for users to express their opinions and experiences, which imperceptibly changes the traditional way of communication, business cooperation, and lifestyle. Social media not only affects individuals but also influences the business world (Bi, 2009). The appearance of social media has laid the foundation for the emergence of new and efficient business models. Companies can use existing social media strategies to retain existing consumers, attract new consumers to increase sales, or use social media to display product information for marketing purposes (Gong, 2018) . Today, a new direction of e-commerce development is socialized commerce. Socialized commerce is often defined as the use of Internetbased media to engage users through online markets or communities in activities that sell, purchase, compare, and share information about products or services. Socialized business has three underlying trends in general: adding business features to social media such as Facebook and Weibo; adding social elements to e-commerce sites such as Amazon and JD; and using social media traditional offline businesses to improve performance. Socialized commerce has changed the role of consumers (Chen, 2013). Consumers have stronger bargaining power through social network cooperation. Therefore, e-commerce has gradually shifted from the original product-oriented platform to the usercentered platform.

The practical significance of this article is as follows: with the rapid development of the Internet, more and more people tend to obtain product information and service information through the Internet. Consumers also tend to leave personal evaluation of products on the Internet platform after consumption, providing other consumers with a basis for reference. Based on the consumer's point of view, before deciding whether to purchase a product, the Internet word of mouth can be used to make a clearer judgment on the purchased product, so as to avoid blind decision-making and avoid unknown risks in the consumption process. The Business Side, consumers can make reasonable and effective improvements to products based on consumers' relevant evaluation and evaluation of products and can effectively improve sales and shape a good corporate image. Secondly, the Internet word of mouth to a certain extent plays a role in propaganda. Enterprises can do product promotion through the e-commerce platform, which can save some of the propaganda expenses. Therefore, the Internet word of mouth plays a role in linking enterprises, existing consumers, and potential consumers to the same platform, which is the significance of this research. This paper explores the influence of the Internet word of mouth on consumers' attitudes and consumers' decision-making process. It plays a guiding role in the process of consumers' consumption and provides a direction for enterprises to enhance their competitive advantages.

The theoretical significance of this article includes the following two points. First, we comprehensively constructed a model of the impact of the Internet word of mouth on consumer purchasing decisions. In the past, research on the impact of the Internet word of mouth on consumers mainly draws on the two-factor impact model or the dual-path model. Based on the Stimuli-Organism-Response (SOR) stimulus model and the Technology Acceptance Model (TAM Model), this paper comprehensively constructs the impact model of the Internet word of mouth on consumer behavior. The model considers various influencing factors, comprehensively expounds the mechanism of the Internet word of mouth impact on consumer behavior and validates the proposed research hypotheses and models through empirical analysis.

In the past, research on the Internet word of mouth mainly studied the influence of word-of-mouth information on consumers' motivation and willingness to purchase a product. Few scholars have studied how word-of-mouth information works. This paper expects that the Internet word of mouth (consumer's source level and acceptance level) indirectly affects consumer behavior by influencing consumer attitudes.

In the context of the vigorous development of social business, the commercial application and academic research of word of mouse catch the attention of managers and scholars. Since the word of mouse information can reduce consumer perceived risk and uncertainty, it plays a crucial role in the formulation of consumer purchasing decisions. Some scholars have studied that social interaction in the 
form of export monuments is a prerequisite for the success of the social business. Lin (2017) and other scholars have found that word of mouse research is divided into four categories: the useful review information, the impact of information retrieval, the impact of trust in word of mouse, and the differences in social media usage patterns and factors of word of mouse adoption.

At present, the majority of social business websites have two types of platforms: an e-commerce website with product sales as the primary purpose or a social media website with social interaction and information sharing as the core functions. The first platform comes from traditional ecommerce. The disclosure of social information is minimal, but the amount of word-of-mouth information such as product reviews is enormous.

The other platform comes from the added commercial function of traditional social media. The degree of user social information disclosure is high, and the frequency of user interaction is high; however, the amount of word of mouse information related to products is small. Most of the current research does not make a clear distinction between the types of word of mouse information in these two types of websites and even considers both as equivalent relationships. However, some scholars have found that the differences between these two types of platforms will also lead to the impact of the published word of mouse information on consumers' product judgments and purchasing decisions. The channel of word of mouse communication has played a critical role in its influence. However, existing research has not explored enough the choice and the influence of word of mouse channels on consumers. Thoroughly, research on word of mouse platforms or channels has become a new trend in the field of electronic word of mouse.

Therefore, this paper will explore the differences between the purchase targeted e-commerce websites and the social interaction media in the context of socialized commerce as the primary function, and it will also explore the differences in electronic word of mouse to answer the following questions: First, how does the word of mouse affect the attitude of consumers in e-commerce shopping platforms? Second, how does the word of mouse in the ecommerce shopping platform affect consumer decisionmaking? Third, do consumer attitudes play an intermediary role in word of mouse and consumer decision-making.

\section{Literature Review}

\subsection{Word of mouse}

Traditional word-of-mouth is the transmission of product information between people concentrated offline before the advent of the Internet, a topic extensively researched by scholars. The traditional definition of word-of-mouth by Arndt (1967) appears in the study of "The Impact of Consumer Talk About New Products on Product Innovation Diffusion." $\mathrm{He}$ emphasizes its two characteristics: noncommercial and verbal communication, which is believed to be the non-commercial, verbal communication between sender and recipient of the information on products, services, or brand information. Based on this, Westbrook (1987) extended the definition of traditional word-of-mouth perception, expanding the media range of word-of-mouth communication from "verbal way" to all "informal ways." Next, Buttle (1998) defines the sender of word-of-mouth. Soon after, with the development of technology, many companies use virtual technology for marketing. With the rapid development of information technology and especially the growing popularity of the Internet, the content of WoM research has changed accordingly. Traditional word ofmouth restricts the dissemination of information to face toface oral communication, whereas the emergence of the Internet provides a new way for information dissemination. Word-of-mouth communication can now use the Internet to complete non-face-to-face information exchange- the so called Word of Mouse.

Referring back to the study of word of mouth by scholars at domestic level and abroad, Stauss (1997) is the first person to elaborate on the Internet word of mouth from the perspective of marketing. He pointed out that customers will use the message board of the company website to inquire about product information or complain about or praise the company for related matters, and, on this basis, the company explores the business opportunities and challenges caused by the increase in network communication between consumers. Furthermore, he also believes that consumers may extend their perception of service quality to a global scale with the Internet technology. This non-commercial communication using the Internet is also known as word of mouse. The new word-of-mouth form defined by Chatterjee (2001) is the "Internet word-of-mouth," which means consumers complete purchasing their products and brands through communication platforms such as online bulletin boards or instant messaging tools such as MSN. Datte (2005) pointed out that the Internet word of mouth refers to the communication between most potential and actual consumers about their consumption experience of products or services in a network environment. Chinese researchers did not start WoM research until the beginning of the 21 st century. However, in recent years, with the increasing popularity of the Internet, domestic scholars have begun to pay attention to the phenomenon. Huang and Zhu (2003) define word-of-mouth from the perspective of marketing. As the communicator does not process the information of a particular product or brand, and the recipients obtain information by explicit or implicit means. Therefore, it is a two-way interactive communication behavior that changes attitudes and purchase behaviors. 
Zhang and Dong (2008) pointed out that Internet wordof-mouth is a natural form of communication in which Internet users communicate and exchange experiences and evaluations of products, brands, or services through online channels. Chen (2008) in their research believes that the online word of mouth is a positive or negative evaluation of products, brands, or services published by consumers on the Internet. Bi (2009) defines the Internet word-of-mouth as using online channels by online users to transmit and exchange product information or service information in the form of text, pictures, images, and audio. Summarizing the definition of the Internet word-of-mouth by previous researchers, this paper defines the Internet word-of-mouth as follows: potential consumers or current consumers who use the Internet to evaluate products, brands, services, and feelings through text, pictures, sounds, images, and other forms of communication. The word of mouse defined in this study is the word-of-mouth information disseminated by customers on the Internet after word-of-mouth marketing on an e-commerce platform. It is also a force that cannot be controlled by word-of-mouth senders.

\subsection{Consumer attitudes}

The model adopted in consumer attitude research is the ABC model (Eagly \& Chaiken 1998, Van den Berg, Manstead, Van der Pligt, \& Wigboldus, 2006), which includes three elements: Affects, Behavior, and Cognition. In the field of advertising, when it comes to the influence of advertising on consumer attitudes, the impact path includes three factors: advertising attitude, brand attitude, and purchase intention. These three are the process of continuous progress. Consumers first form an advertising attitude, then a brand attitude, and, ultimately, the level of purchase willingness. In the same way, contrary word of mouse and advertising are all types of information communication, so contrary word of mouse will also have similar effects on consumers. "Credit" means the degree of consumer trust in contrary word of mouse. The credibility here is not the influence of the information itself, but the intuitive judgment that consumers can perceive. Moreover, Dobele and Lindgreen (2010) used "credibility" as a mediator in the study of word-of-mouth, focusing on the impact on brand cognition and brand sentiment, and then they studied two factors that influenced the internal mechanism of consumer attitudes. The model of attitude consists of three main components: cognitive, emotional, and conscious components.

\subsection{Brand cognition and brand emotion}

According to Baron (1988), attitudes include three aspects: Cognitive, Affective, and Behavior. The corresponding consumer attitude toward products and brands has brand cognition, brand emotion, and purchase intention. Brand cognition has five components: perceived quality, perceived value, brand image, trust, and brand promise. Aaker (1997) believes that brand recognition is a perception of all the brand's information and covers all aspects of brand equity. There are three types of brand association: the association between brand attributes, the association between brand product interests, and the association between brand attitudes. He believes that brand associations must have the following characteristics: higher intensity, high praise, and unique brand. Chauduri and Holbrook (2001) define the brand attitude of cognitive components as "brand cognition", which is the degree of practicality that consumers believe brand cognition can provide. The brand attitude of emotional components is called "brand emotion," that is, consumers' immediate subjective emotional feelings toward the brand. Brand cognition refers to the knowledge and perception formed by consumers after they come into contact with products or brands. Brand emotion refers to the instant emotional components produced by consumers toward brands and products, including the overall, direct, or indirect evaluation of consumers. Combining the above and the particularity of the network platform, this paper defines brand cognition as the perceptual and practical level of the general audience's function for the brand or product. By contrast, brand emotion is the instant emotional component generated by the consumer on the product or brand.

\subsection{Consumers' willingness to make decisions}

Behavioral willingness, also known as behavioral tendencies, is consumers' motivation to take specific actions in the future and is a statement that connects consumers' states and future behaviors (Peter \& Olson, 1996). Ajzen and Fishbein (1980) argue that willingness to act refers to the extent of a customer's motivation to exhibit a certain behavior. It is often spontaneous, and there is no other external factor that interferes with this positive willingness to induce the customer to perform certain behaviors. The stronger the willingness to engage in the act, the more likely it is to perform the act. Ajzen (2002) pointed out that behavioral willingness can describe behavior more accurately than attitudes, feelings, and beliefs. Therefore, it can predict whether consumers will exhibit certain behaviors in the future. Fishbein (1992) pointed out that research on consumer decision-making has been carried out for many years. Traditional research methods divide the consumer's purchase decision-making process first and then conduct research and analysis on each part of the process to judge its influencing factors. A significant difficulty of these traditional methods is that the behavior of consumers is difficult to track. Even if the researcher can trace the whole process, the cost is very high. 
Many scholars indirectly study behavioral willingness as the indicator of consumer behavior, due to its prediction accuracy. In the past, when scholars defined behavioral intentions, they usually emphasized the possibility of consumers engaging in certain behaviors. They believed that when consumers got specific information or certain stimuli, their mental state would change, thus affecting their willingness to act. However, this does not mean that their research has no differences. Different scholars have different ideas when they study consumer behavior in various industries and fields. The difference is whether the consumer has had a consumption behavior in a company before the appearance of behavioral willingness. The concept by Ajzen and Fishbein (1980) does not emphasize whether consumers have had consumer behavior first, but it does not deny that consumers may know the company's products in advance. This study selects Ajzen's argument. When defining the willingness to act, it does not explicitly emphasize whether consumers have had any consumption behaviors for a particular company or specific product. In this study, consumers' willingness to make decisions is defined as the possibility of behavior related to the company and word-ofmouth products after the consumer received WoM.

\subsection{Hypothesis Development}

\subsubsection{Source level of Word of Mouse}

Word of Mouse is a description of objective facts or the evaluation or recommendation from the perspective of consumers. It describes the attributes of the product. WoM is accurately defined and tested with objective criteria. It is an objective and rational commentary on the information publisher. However, consumers' perception or recommendation contains abundant subjective emotions which can be the expression of purchase experience in a particular product or service, such as what happened during the purchase process and how they felt. Different types of WoM content have a particular influence on consumers, and the information should contain the product itself and the emotions of publishers, where there is a high degree association with customers. Doll and Torkzadeh (1988), all use the comprehensiveness and relevance of its content as a dimension to determine the credibility of WoM. Therefore, this study proposes the hypothesis:

H1: Positive WoM is positively related to consumer attitudes. H1A: The credibility of the WoM source is positively related to consumer attitudes.

H1B: The Professionalism of WoM content is positively related to consumer attitudes.

H2: Positive WoM is positively related to consumer decision-making.

H2A: The credibility of the WoM source is positively related to consumer decisions.

H2B: The Professionalism of WoM content is positively related to consumer decisions.

\subsubsection{Recipient level of Word of Mouse}

Product involvement refers to the importance and relevance of a consumer's perception of a product based on its own needs. Cacioppo, Petty, and Morris (1983) proposed a model of exceptional processing possibility that indicates the professional level of consumers will affect the path of consumers processing information. When the professionalism of customer is high, they are inclined to choose the central path, that is, spend more efforts to process information. Herr, Wartinger, Fair, Oettgen (1992) believe that WoM of well-known brands has less effect on customers' information process. However, the WoM is an essential factor that affects consumer attitudes for niche brands. Gilly (1998) also believe that the WoM has less effect on higher-level professionalism of recipients. They have a strong willingness to search for WoM information actively. Therefore, this study proposes the hypothesis:

H1C: Product involvement of WoM recipients is positively related to consumer attitudes.

H2C: Product involvement of WoM recipients is positively related to consumer decision-making.

H1D: The professionalism of WoM recipients is positively related to consumer attitudes;

H2D: The professionalism of WoM recipients is positively related to consumer decision-making.

\subsubsection{Consumer attitude as the intermediary variables}

Burton (1998) found that although there is a positive correlation between customer's attitude of private brand and private brand purchase willingness, due to the different consumer groups, the market share occupation of private brands is still low.

$\mathrm{Wu}$ and $\mathrm{Li}$ (2011) found that price, store image, brand, and internal clue factors have a significant influence on consumer cognition attitude, and the most critical factor affecting purchase intention is a cognitive attitude. The retail store image will influence consumers' attitude towards their brands. Consumers have a slowing effect on the familiarity of their own branded products. For food and clothing products, the less familiar consumers are, the stronger the explanatory power of the aperture effect model. Usually, a person's desire to purchase a product goes through a cognitive phase and an attitude phase.

Therefore, this paper introduces two variables of brand cognition and brand emotion in consumer attitude to verify the mediation effect of consumer attitude on Internet wordof-mouth to consumer decision-making.

Willingness refers to the subjective possibility and 
probability of an individual taking action, which originated from the study of psychology. Bagozzi and Burnkrant (1979) define consumer's willingness as the individual's tendency to act on the product. Dodds (1991) believes that it is a predictor of consumer purchases and the possibility of purchasing the product. Based on the expansion of information model refinement, this paper discussed the influence of brand cognition and brand emotion on consumers' purchase willingness during the process of consumer attitude formation.

Consumers now become more willing to actively search for information related to products, brands or enterprises through the passive acceptance of information related to products or brands in the past. Brand sentiment can increase the positive brand attitude of consumers and strengthen the brand association of consumers, which has a positive impact on consumers' willingness to purchase. Based on the review of brand perceptions and brand emotion and consumer purchase willingness, this study proposes the following hypothesis:

H3: Consumer attitude is positively related to consumer decision making

H3A: Brand cognition is positively related to consumer decision making

H3B: Brand emotion is positively related to consumer decision making

In order to study the intermediary effect of consumer attitudes, we divide consumer attitude into brand hypothesis and analysis of brand effect and consumer behaviour. Assume the following:

H4: Consumer attitude has an intermediary effect on Word of Mouse and consumer decision-making.

H4A: Brand cognition has an intermediary effect on Word of Mouse and consumer decision-making.

H4B: Brand emotion has an intermediary effect on Word of Mouse and consumer decision-making.

\section{Research Model and Methods}

\subsection{Model}

Based on the aforementioned literature analysis, this study explores the differences between the consumer's perceptions and purchase intentions from different sources of online entertainment information based on the EBM theoretical framework. One of the critical differences between e-commerce websites and traditional industry sales models is the "relationship strength" between users. It suggests the relationship between the publisher and the recipient of the information. In an e-commerce website, the publisher of the product is a stranger to other consumers, and there is barely an opportunity for them to talk face to face with each other. However, in traditional media, users often know each other in real life, which provides them with opportunities to communicate. This implies that the word of mouse communication in e-commerce websites is weak. Moreover, the amount of personal information posted on e-commerce websites is much less than that posted on social media. Furthermore, most e-commerce users are anonymous and have a few user personal information pages. The EBM model emphasizes consumer purchase decisions as a problem-solving process that divides consumer purchase decisions into five phases (Engel, Blackwell, \& Miniard, 1995). At each stage, consumers can accept word of mouse information from others through the Internet and then form an attitude through their purchase process. Finally, consumers synthesize attitudes at each stage to make a decision. The empirical analysis in this paper focuses on one stage rather than the whole decision-making process. We chose consumer attitude as the dependent variable, which is different from previous research where it is an independent variable. Therefore, this study will explore how different types of WoM content and sources affect consumer attitudes and purchase decisions.

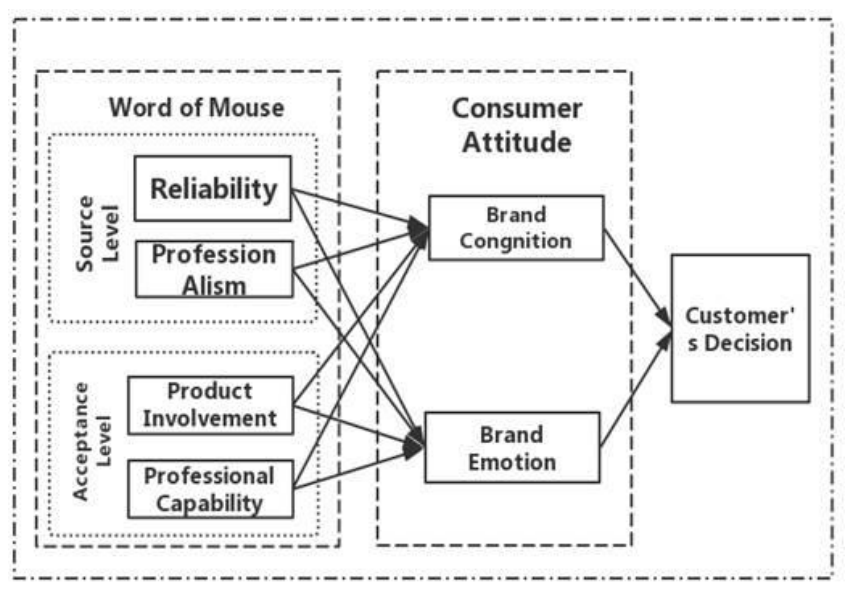

Figure 1: Research Model

\subsection{Instrumental development}

As a new marketing strategy, WoM affects not only the success of the company but also the purchasing behavior of consumers. In previous studies, we found that the scale of the factors affecting WoM has two aspects. The first aspect affecting WoM is the credibility of content and source. Datta (2005), Sun (2009), and other scholars believe that the credibility of WoM information senders includes the dimension of professional competence and reliability, in other words senders provide positive information and 
deliver qualified performance. The second aspect affecting WoM's recipient, which contains the product involvement and the professionalism of recipients (Zhang, 2013; Christy, 2008; Wen, 2011). Keller (1998) conducted a detailed and an in-depth study of brand cognition, which divided brand cognition into two dimensions: brand cognition and brand image, in which brand cognition includes brand recall and brand recognition. Aaker (1997) does not make a clear definition of brand emotion but instead uses it as part of brand association. Netemeyer, Krishnan, Pullig, Wang, Yagci, Dean, Ricks, and Wirth (2004) extended the distinction of brand emotions and proposed methods for measuring the customer's particular emotional value toward the brand. This paper selects Zhang (2013) scale to analyze consumer decision-making, which involves purchase decisions and decision-making times. All measurements in this study are based on previous studies and are measured with five-point Likert-type scales (1= "strongly disagree" and $5=$ "strongly agree").

\subsection{Data collection and analysis methods}

Data were collected in 14 cities. The survey used structured questionnaires from June 7 to July 28, 2019. A total of 400 questionnaires were designed (200 online and 200 offline), and 376 questionnaires were received (including 181 online and 195 offline), where 336 valid questionnaires were selected (including 156 online and180 offline). In terms of gender distribution, we noticed that most of the samples were "male" with a ratio of 54.5\%, while the proportion of female samples was $45.5 \%$. Regarding age distribution, most of the samples were "23-27 years old" with a ratio of $33.9 \%$. Meanwhile, $48.5 \%$ of the samples were "undergraduate," and $40.2 \%$ of the samples were "college" students. College students are the group with the highest network usage rate in all aspects, and they pay more attention to WoM. Therefore, this paper chose them to be the test group. As both iPhone XS and Huawei P30 have similar product competitiveness, we surveyed iPhone XS and Huawei P30 phone users. $59.2 \%$ of the samples chose Huawei P30, and $40.8 \%$ of the samples chose iPhone XS. In terms of purchase time, "two months" accounted for a maximum of $34.5 \%$. Reasons for experimental product selection: According to "2018 Accenture China Consumer Insights - New Consumption New Forces," the 20-year-old group has a $41 \%$ active consumption intensity in high-tech electronic products represented by mobile phones, which is the highest among all types of products. In combination with the test group selected in this experiment, the mobile phone is the experimental product. In the range of similar types of mobile phones, this article selects two mobile phones with a good reputation and similar prices in China: iPhone XS and Huawei P30. In this study, we used SPSS 25.0 and AMOS to analyze the general characteristics of the samples.

\section{Results}

\subsection{Analysis of reliability and validity}

Based The results of an exploratory factor analysis of WOM and Consumer attitude, consisting of 32 items, are as follows. The eigenvalue of each factor is above 1.0, and the factor loading is also appropriate. In addition, Cronbach's $\alpha$ is 0.8 or more, and reliability is secured. It comprehensively indicates that data reliability is valid and can be used for further analysis.

Table 1: Pearson Correlation

\section{Pearson Correlation}

\begin{tabular}{|c|c|c|c|c|c|c|c|c|c|}
\hline & Mean & S.D & $\begin{array}{l}\text { Brand } \\
\text { Cogation }\end{array}$ & $\begin{array}{l}\text { Brand } \\
\text { Emotion }\end{array}$ & Credibility & Professionalism & $\begin{array}{l}\text { Product } \\
\text { intake }\end{array}$ & $\begin{array}{c}\text { Professional } \\
\text { Ability }\end{array}$ & $\begin{array}{l}\text { Consumer } \\
\text { Decision }\end{array}$ \\
\hline Brand Cogation & 3.883 & 1.043 & 1 & & & & & & \\
\hline Brand Emotion & 3.883 & 1.024 & $0.915^{\star *}$ & 1 & & & & & \\
\hline Credibility & 3.863 & 1.033 & $0.900^{\star *}$ & $0.897^{\star *}$ & 1 & & & & \\
\hline Professionalism & 3.862 & 1.020 & $0.924^{\star *}$ & $0.921^{\star *}$ & $0.923^{\star \star}$ & 1 & & & \\
\hline Product intake & 3.871 & 1.046 & $0.906^{\star *}$ & $0.903^{\star *}$ & $0.870^{* *}$ & $0.903^{* *}$ & 1 & & \\
\hline $\begin{array}{c}\text { Professional } \\
\text { Ability }\end{array}$ & 3.835 & 1.066 & $0.913^{\star *}$ & $0.893^{* *}$ & $0.854^{\star *}$ & $0.903^{* *}$ & $0.888^{* *}$ & 1 & \\
\hline $\begin{array}{l}\text { Consumer } \\
\text { Decision }\end{array}$ & 3.851 & 1.065 & $0.918^{\star *}$ & $0.916^{* *}$ & $0.894^{* *}$ & $0.925^{\star *}$ & $0.890^{* *}$ & $0.902^{* *}$ & 1 \\
\hline
\end{tabular}

Note: ${ }^{*} p<0.05,{ }^{* *} p<0.01,{ }^{* * *} p<0.001$ 
We noticed that the commonality values of all research items were higher than 0.4, which indicated that the research item information was effectively extracted. Furthermore, the $\mathrm{KMO}$ value is 0.991 , which is greater than 0.6 . This means the dataset is valid. The cumulative variance interpretation rate was $77.713 \%>50 \%$ after rotation. The result suggests that the information of research items can be extracted efficiently. The following step is conducting the CFA of each dimension to confirm whether they are suitable for the current study through SPSS and AMOS. The goodness-of-fit indexes suggest that the proposed model has an adequate fit $(\mathrm{x} 2=473.619, \quad \mathrm{df}=443, \quad \mathrm{CFI}=.997, \quad \mathrm{NFI}=.958$, RMSEA $=.014)$. It comprehensively explains the optimization process of model construction.

\subsection{Analysis results}

\subsubsection{Correlation Analysis}

Based on the following Table1, we applied correlation analysis to study the correlation between brand cognition, brand emotion, credibility, professionalism, product involvement, professional capability, and consumer decision. The result shows that brand cognition, brand emotion, credibility, professionalism, product involvement, professional capability, and consumer decision are all significant. The representative correlation coefficient values are $0.915,0.900,0.924,0.906,0.913$, and 0.918 .

\subsubsection{Word of Mouse and Consumer Attitude}

The results indicate that the R-squared value of the model is 0.938 , which means all independent variables can explain the $93.8 \%$ change in consumer attitude $(\mathrm{F}=996.159, \mathrm{P}<0.05)$. This indicates that at least one of the independent variables affects consumer attitude.

Furthermore, the multicollinearity test of the model revealed that the VIF values in the model were all less than the threshold of 10.0. The final result of the analysis shows that the regression coefficient of word of mouse is 0.861 $(\mathrm{t}=2.830, \mathrm{P}=<0.05)$, which means that word of mouse will have a significant positive impact on consumer attitude. H1 has been verified. The regression coefficient of credibility is $0.899(\mathrm{t}=2.358, \mathrm{P}<0.05)$, which means that credibility influences consumer attitude. H1 A has been verified. The regression coefficient of professionalism is $0.935(\mathrm{t}=1.548$, $\mathrm{P}<0.05$ ), which means that professionalism influences consumer attitude. H1B has been verified. The results are documented in Table 2.

Table 2: Results of Regression Analysis

\begin{tabular}{|c|c|c|c|c|c|c|c|c|c|}
\hline \multicolumn{10}{|c|}{ Results of Regression Analysis } \\
\hline & \multicolumn{2}{|c|}{$\begin{array}{l}\text { Unstandardized } \\
\text { Coefficients }\end{array}$} & \multirow{2}{*}{$\begin{array}{c}\begin{array}{c}\text { Standardized } \\
\text { Coefficients }\end{array} \\
\text { Beta }\end{array}$} & \multirow[t]{2}{*}{$\mathbf{t}$} & \multirow{2}{*}{$\mathbf{p}$} & \multirow[t]{2}{*}{ VIF } & \multirow[t]{2}{*}{$\mathbf{R}^{2}$} & \multirow[t]{2}{*}{ Adj $R^{2}$} & \multirow[t]{2}{*}{$\mathbf{F}$} \\
\hline & B & Std. Error & & & & & & & \\
\hline Constant & 0.108 & 0.056 & - & 1.947 & 0.052 & - & \multirow{6}{*}{0.938} & \multirow{6}{*}{0.937} & \multirow{6}{*}{$\begin{array}{l}996.159 \\
\left(0.000^{* \star}\right)\end{array}$} \\
\hline Word of Mouse & 0.861 & 0.304 & 0.853 & 2.83 & $0.321^{\star *}$ & 0.76 & & & \\
\hline Credibility & 0.899 & 0.021 & 0.918 & 2.358 & $0.013^{* *}$ & 1 & & & \\
\hline Professionalism & 0.935 & 0.018 & 0.943 & 1.548 & $0.212^{\star *}$ & 0.935 & & & \\
\hline Product intake & 0.894 & 0.02 & 0.924 & 4.204 & $0.234^{* *}$ & 1 & & & \\
\hline $\begin{array}{c}\text { Professional } \\
\text { Ability } \\
\end{array}$ & 0.03 & 0.085 & 0.032 & 0.357 & 0.722 & 3.12 & & & \\
\hline
\end{tabular}

Note: ${ }^{*} p<0.05,{ }^{* *} p<0.01,{ }^{* * *} p<0.001$

Dependent variable : Consumer Attitude

The regression coefficient of product involvement is $0.894(\mathrm{t}=4.204, \mathrm{P}<0.05)$, which means that product involvement has an impact on consumer attitude. H1C has been verified. The regression coefficient of professional capability is $0.030(\mathrm{t}=0.357, \mathrm{P}=0.722>0.05)$, which means that professional capability does not affect consumer attitude. Therefore, hypothesis H1D does not hold.

\subsubsection{Word of Mouse and Consumer Decision}

The model was evaluated using the F-test, and it passed the F-test $(\mathrm{F}=672.237, \mathrm{P}<0.05)$, which means that at least one of the independent variables will affect consumer decision. The final result of the analysis shows that the regression coefficient of WoM is $1.003 \quad(t=52.174$, $\mathrm{P}=0.000<0.01$, which means that WoM has a significant positive impact on consumer decision. The regression coefficient of credibility is $0.199(\mathrm{t}=3.980, \mathrm{P}=0.000<0.01)$, which means that credibility has a significant positive impact on consumer decision. The regression coefficient of professionalism is $0.371(\mathrm{t}=5.878, \mathrm{P}=0.000<0.01)$, which means that professionalism has a significant positive impact on consumer decision. The regression coefficient of product 
involvement is $0.150(\mathrm{t}=3.136, \mathrm{P}=0.002<0.01)$, which means that product involvement has a significant positive impact on consumer decision. The regression coefficient of professional capability is $0.286(\mathrm{t}=6.221, \mathrm{P}=0.000<0.01)$, which means that professional capability has a significant positive impact on consumer decision. In summary, the analysis shows that word of mouse, credibility, professionalism, product involvement, and professional capability all have significant positive influences on consumer decision. Therefore, hypotheses H2, H2A, H2B, $\mathrm{H} 2 \mathrm{C}$, and H2D all passed. The results are documented in Table 3.

Table 3: Results of Regression Analysis

\begin{tabular}{|c|c|c|c|c|c|c|c|c|c|}
\hline \multicolumn{10}{|c|}{ Results of Regression Analysis } \\
\hline & \multicolumn{2}{|c|}{$\begin{array}{l}\text { Unstandardized } \\
\text { Coefficients }\end{array}$} & \multirow{2}{*}{\begin{tabular}{|c|}
$\begin{array}{c}\text { Standardized } \\
\text { Coefficients }\end{array}$ \\
Beta
\end{tabular}} & \multirow[t]{2}{*}{$t$} & \multirow{2}{*}{$\mathbf{p}$} & \multirow[t]{2}{*}{ VIF } & \multirow{2}{*}{$\mathbf{R}^{2}$} & \multirow{2}{*}{ Adj $R^{2}$} & \multirow[t]{2}{*}{$\mathbf{F}$} \\
\hline & B & Std.Error & & & & & & & \\
\hline Constant & -0.029 & 0.078 & - & -0.368 & 0.713 & - & \multirow{6}{*}{0.89} & \multirow{6}{*}{0.889} & \multirow{6}{*}{$\begin{array}{l}672.237 \\
\left(0.000^{\star *}\right)\end{array}$} \\
\hline Word of Mouse & 1.003 & 0.019 & 0.944 & 52.174 & $0.234^{\star *}$ & 1 & & & \\
\hline Credibility & 0.199 & 0.05 & 0.193 & 3.98 & $0.123^{\star \star}$ & 4.104 & & & \\
\hline Professionalism & 0.371 & 0.063 & 0.355 & 5.878 & $0.256^{\star *}$ & 6.03 & & & \\
\hline Product intake & 0.15 & 0.048 & 0.147 & 3.136 & $0.231^{\star *}$ & 6.662 & & & \\
\hline $\begin{array}{c}\text { Professional } \\
\text { Ability }\end{array}$ & 0.286 & 0.046 & 0.286 & 6.221 & $0.145^{\star *}$ & 6.39 & & & \\
\hline
\end{tabular}

Note: ${ }^{*} p<0.05,{ }^{* *} p<0.01,{ }^{* * *} p<0.001$

Dependent variable : Consumer Attitude

\subsubsection{Consumer Attitude and Consumer Decision}

The model was evaluated using the F-test, and it passed the F-test $(\mathrm{F}=1197.736, \mathrm{P}<0.05)$, which means that at least either consumer attitude, brand cognition, or brand emotion will impact consumer decision. The final result of the analysis shows that the regression coefficient value of brand cognition is $0.500(\mathrm{t}=10.291, \mathrm{P}=0.000<0.01)$. Therefore, brand cognition has a significant positive influence on consumer decision. Consumer attitude has a regression coefficient of $0.987(\mathrm{t}=49.016, \mathrm{P}=0.000<0.01)$, which means that consumer attitude has a significant positive influence on consumer decision. The regression coefficient of brand emotion is $0.487(\mathrm{t}=9.858, \mathrm{P}=0.000<0.01)$, which suggests that brand emotion has a significant positive influence on consumer decision. The results are documented in Table 4 . In summary, consumer attitude, brand cognition, and brand emotion all have significant positive influences on consumer decision. Therefore, H3, H3A, and H3B are all verified.

Table 4: Results of Regression Analysis

\begin{tabular}{|c|c|c|c|c|c|c|c|c|c|}
\hline \multicolumn{10}{|c|}{ Results of Regression Analysis } \\
\hline & \multicolumn{2}{|c|}{$\begin{array}{l}\text { Unstandardized } \\
\text { Coefficients }\end{array}$} & \multirow{2}{*}{\begin{tabular}{|c|}
$\begin{array}{c}\text { Standardized } \\
\text { Coefficients }\end{array}$ \\
Beta
\end{tabular}} & \multirow[t]{2}{*}{$\mathbf{t}$} & \multirow[t]{2}{*}{$\mathbf{p}$} & \multirow[t]{2}{*}{ VIF } & \multirow[t]{2}{*}{$\mathbf{R}^{2}$} & \multirow[t]{2}{*}{ Adj $R^{2}$} & \multirow[t]{2}{*}{$\mathbf{F}$} \\
\hline & B & Std. Error & & & & & & & \\
\hline Constant & 0.019 & 0.081 & - & 0.232 & 0.817 & - & \multirow{4}{*}{0.878} & \multirow{4}{*}{0.877} & \multirow{4}{*}{$\begin{array}{l}1197.736 \\
\left(0.000^{* *}\right)\end{array}$} \\
\hline Consumer Attitude & 0.988 & 0.02 & 0.937 & 48.922 & $0.000^{* *}$ & 1 & & & \\
\hline Brand Cogation & 0.5 & 0.049 & 0.489 & 10.291 & $0.000^{* *}$ & $1_{1} 6.16$ & & & \\
\hline Brand Emotion & 0.487 & 0.049 & 0.468 & 9.858 & $0.000^{* *}$ & 1 & & & \\
\hline
\end{tabular}

Note: ${ }^{*} p<0.05,{ }^{* *} p<0.01,{ }^{* * *} p<0.001$

Dependent variable : Consumer Decision

\subsubsection{The Intermediary Influence of Consumer Attitude}

Based on the following Table 5 and Table 6, we take WoM as an independent variable and conduct linear regression analysis of consumer decision as a dependent variable. The R-squared value of the model is 0.891 , which means that WoM can explain the $89.1 \%$ change in consumer decision. The model was evaluated using the F-test, and it 
passed the F-test $(\mathrm{F}=2722.166, \mathrm{P}<0.05)$, which means that word of mouse can influence consumer decision. Finally, the result of the analysis shows that the regression coefficient of
WoM is 1.003 , which means it has a significant positive influence on consumer decision ( $\mathrm{t}=52.174, \mathrm{P}=0.000<0.01$ ).

Table 5: Results of Regression Analysis

\begin{tabular}{|c|c|c|c|c|c|c|c|c|}
\hline \multicolumn{9}{|c|}{ Results of Hierarchical Regression Analysis } \\
\hline & \multicolumn{4}{|c|}{ Hierarchical1 } & \multicolumn{4}{|c|}{ Hierarchical2 } \\
\hline & B & Std.error & $\mathbf{t}$ & $\mathbf{P}$ & B & Std.error & $\mathbf{t}$ & $\mathbf{P}$ \\
\hline Constant & -0.015 & 0.077 & -0.191 & 0.849 & -0.062 & 0.074 & -0.832 & 0.406 \\
\hline Word of Mouse & $1.003^{* *}$ & 0.019 & 52.174 & 0 & $0.620^{* *}$ & 0.073 & 8.447 & 0 \\
\hline Consumer Attitude & & & & & $0.392^{\star \star}$ & 0.073 & 5.391 & 0 \\
\hline $\mathrm{R}^{2}$ & \multicolumn{4}{|c|}{0.891} & \multicolumn{4}{|c|}{0.899} \\
\hline Adj $R^{2}$ & \multicolumn{4}{|c|}{0.89} & \multicolumn{4}{|c|}{0.899} \\
\hline$F$ value & \multicolumn{4}{|c|}{$2722.166\left(0.000^{* \star}\right)$} & \multicolumn{4}{|c|}{$1489.983\left(0.000^{\star \star}\right)$} \\
\hline$\Delta R^{2}$ & \multicolumn{4}{|c|}{0.891} & \multicolumn{4}{|c|}{0.009} \\
\hline$\Delta \mathrm{F}$ Value & \multicolumn{4}{|c|}{$2722.166\left(0.000^{\star \star}\right)$} & \multicolumn{4}{|c|}{$29.065\left(0.000^{* \star}\right)$} \\
\hline
\end{tabular}

Note: ${ }^{*} p<0.05,{ }^{* *} p<0.01,{ }^{* * *} p<0.001$

Dependent variable : Consumer Decision

Table 6: Results of Regression Analysis

\begin{tabular}{|c|c|c|c|c|c|c|c|c|}
\hline \multicolumn{9}{|c|}{ Results of Hierarchical Regression Analysis } \\
\hline & \multicolumn{4}{|c|}{ Hierarchical1 } & \multicolumn{4}{|c|}{ Hierarchical2 } \\
\hline & B & Std.error & $\mathbf{t}$ & $\mathbf{P}$ & B & Std.error & $\mathbf{t}$ & $\mathbf{P}$ \\
\hline Constant & -0.015 & 0.077 & -0.191 & 0.849 & -0.063 & 0.074 & -0.847 & 0.398 \\
\hline Word of Mouse & $1.003^{\star *}$ & 0.019 & 52.174 & 0 & $0.622^{*}$ & 0.074 & 8.441 & 0 \\
\hline Consumer Attitude & & & & & $0.181^{* *}$ & 0.058 & 3.116 & 0.002 \\
\hline $\mathrm{R}^{2}$ & \multicolumn{4}{|c|}{0.891} & \multicolumn{4}{|c|}{0.9} \\
\hline Adj $R^{2}$ & \multicolumn{4}{|c|}{0.89} & \multicolumn{4}{|c|}{0.899} \\
\hline$F$ value & \multicolumn{4}{|c|}{$2722.166\left(0.000^{* \star}\right)$} & \multicolumn{4}{|c|}{$990.715\left(0.000^{\star \star}\right)$} \\
\hline$\Delta R^{2}$ & \multicolumn{4}{|c|}{0.891} & \multicolumn{4}{|c|}{0.009} \\
\hline$\Delta \mathrm{F}$ Value & \multicolumn{4}{|c|}{$2722.166\left(0.000^{\star \star}\right)$} & \multicolumn{4}{|c|}{$14.550\left(0.000^{\star \star}\right)$} \\
\hline
\end{tabular}

Note: ${ }^{*} p<0.05,{ }^{* *} p<0.01,{ }^{* * *} p<0.001$

Dependent variable : Consumer Decision

To sum up, WoM has a significant positive influence on consumer decision. Model 2: After adding brand cognition and brand emotion to Model 1, the change in F-value is significant $(p<0.05)$, which means that brand cognition and brand emotion have an explanatory meaning in this model. Moreover, the R-squared value increases from 0.891 to 0.900 , which suggests that brand cognition and brand emotion can produce a $0.9 \%$ interpretation of consumer decision. The regression coefficient of brand cognition is 0.181 , and the value is significant $(\mathrm{t}=3.116, \mathrm{P}=0.002<0.01)$, which means that brand cognition will have a significant positive influence on consumer decision. The regression coefficient of brand emotion is 0.210 , and the value is significant $(\mathrm{t}=3.779, \mathrm{P}=0.000<0.01)$, which suggests that brand emotion will have a significant positive influence on consumer decision. Thus, hypothesis H4A has holds and is fully intermediate. Hypothesis H4B has hold but is partially intermediate

\section{Conclusions}

\subsection{Discussion}

This study attempts to develop and construct the research model of consumer decision-making. The independent variable WoM includes the source level and the receiving 
level. The source level is composed of reliability and professionalism. The receiving level is composed of product involvement and professional capability level combined. The introduction of consumer attitude as a mediator variable and consumer decision-making as a dependent variable put forward the assumption of the relevant impact relationship.

In the theoretical model of this paper, we selected Wo, recipients and WoM sources when studying the influence of the WoM quality on consumer decision-making. It includes professionalism, credibility, and product involvement. From the results of the empirical analysis, the credibility and professionalism of the WoM have a significant influence on consumer decision-making, and the significance level of both factors is at 0.001 . Product involvement has a significant influence on consumer decision-making in terms of WoM acceptance. However, professionalism does not have any significant influence on consumer decision-making.

Based on the results of this paper, we found that WoM has a significant positive influence on consumer decisionmaking. Therefore, the better the quality of the WoM information, the easier the consumers can understand the relevant information of products and services. Customers will compare gains and losses of products and services based on the WoM information, which generated consumer purchase decisions. This conclusion is consistent with the research results of Hovland (1953), Lee (2008), and other scholars. WoM has a good performance in terms of relevance, timeliness, accuracy, and breadth of products and services. Consumers will have a stable and reliable perception of products and services when exposed to valid WoM information. Furthermore, it helps customers understand the authenticity of products and services, reduces perceived risks, and forms a better trade-off value for products and services.

When studying the influence of WoM on consumer attitudes, based on the results of the empirical analysis, it is shown that it has a significant influence on consumer attitudes, and the significance level of both factors is at 0.001 . It completely suggests that there is a close relationship between WoM and consumer purchase attitude. Therefore, the better the quality of the WoM information, the more details the consumers will receive about products and services. It will encourage consumers to generate consumption behavior eventually. The conclusion of this study is consistent with the research results of Cheung, Lee, and Rabjohn (2008) and Eagly and Chaiken (1993). Therefore, the quality of the WoM information directly affects consumer attitudes.

In the theoretical model of this paper, we take brand cognition and brand emotion as two intermediary variables. Based on the data operation results, brand cognition and brand emotion have significant influences on consumer decision-making, and both act as partial mediators with effective intermediary influences.

This study proposes a conceptual model that explores the relationship between consumer attitudes and consumer behaviors in terms of the source and reception of Internet word of mouth. This finding suggests through empirical research, that the proposed conceptual model can be used to explain the impact of the Internet word of mouth on consumer purchasing decision-making behavior. Moreover, the research results of this study can play a guiding role in related research in the field of the Internet word-of-mouth in the future.

The value of this research for consumers lies in providing valuable judgments for their purchasing decisionmaking behavior by dividing the Internet word of mouth into four dimensions: reliability, professionalism, product involvement, and professional capability. Consumers can accurately distinguish the accuracy and value of the Internet word of mouth based on reliability and professionalism in the judgment of the source of the Internet word of mouth.

This research can enable enterprises that want to change the existing Internet word-of-mouth communication effect to perceive the inadequacies of enterprise products through the channel of Internet word of mouth, and further consumers' preferences and attitudes toward products so that companies can make targeted improvement programs to enhance their competitiveness. Moreover, this study is interesting to companies to consider online word of mouth from the perspective of consumers, thereby improving existing marketing strategies.

With the rapid development of international trade, the Internet has become an essential part of our daily life and continuously affects people's lives. Traditional word-ofmouth communication has shown a new pattern in an online environment. Consumers regard WoM as a valid method to obtain information about products and services. Meanwhile, it helps consumers increase their knowledge of products or services through online channels. Ratchford et al. (2001) argue that consumers can learn about products and services from large-scale, separate, and unfamiliar people through online media. The Internet keeps information transparent and disclosing, and the market dominates from the seller's market to the buyer's market. In the buyer's market environment, whether a merchant can apply communication methods to provide accurate information about the products and services determines the success of one's business. For merchants, WoM marketing costs them a low price, which can improve the competitiveness and the profitability of the business. This paper studies the relationship between the WoM information and consumer decision-making. Furthermore, the research conclusion provides practical significance and value for merchants to develop better WoM marketing and to establish the reliability of WoM websites. 


\subsection{Limitations and future research}

The theoretical and practical implications of this study are as follows. However, it is not without limitations. The subjects of this study were national Internet users who did online shopping and were influenced by WoM. This study obtained data by filling out questionnaires on large forums, post bars, and social networking sites and rewarded participants with mutual visits, mutual questionnaires. However, the three previously mentioned aspects cannot guarantee the accuracy of the respondent's answer. Therefore, these factors may cause a deviation between the questionnaire data and actual situation. Meanwhile, the way of issuing the questionnaire cannot guarantee the randomness of the sample. However, the study does not take into account differences in Internet penetration in different regions and the online habits of Internet users. Moreover, the educational level of the sample is above average, so the research sample cannot represent all WoM recipients to a certain extent. Second, this study divides WoM into source and acceptance. However, the channels of communication are diverse, and each channel of communication may have different influences on WoM communication. Professionalism and credibility are not the only two aspects of senders and recipients. Further research on other dimensions is necessary.

Based on the innovations and research limitations of this study, there are many avenues of further research to pursue. For further research, follow-up research can implement the scenario simulation method to conduct experimental research on WoM to obtain updated and useful influential indicators. Follow-up research can study the influence mechanism of WoM based on the Internet usage data of different provinces or regions in China. Considering that the number of rural Internet users is increasing each year, the research object in future research should cover more professional groups. Moreover, follow-up research can examine the classification of WoM through a specific communication channel such as Weibo.

\section{References}

Aaker, J. L. (1997). Dimensions of brand personality. Journal of marketing research, 34(3), 347-356.

Ajzen, I. (2002). Perceived behavioral control, self-efficacy, locus of control, and the theory of planned behavior 1. Journal of applied social psychology, 32(4), 665-683.

Arndt, J. (1967). Role of Product-Related Conversations in the Diffusion of a New Product. Journal of Marketing Research, 4, 291-295.

Bagozzi, R. P., \& Burnkrant, R. E. (1979). Attitude organization and the attitude-behavior relationship. Journal of Personality and Social Psychology, 37(6), 913-929.
Baron, R. A. (1988). Negative effects of destructive criticism: Impact on conflict, self-efficacy, and task performance. Journal of Applied Psychology, 73(2), 199-207.

Bi, J. D. (2009). An Empirical Study on Internet Word of Mouth Affecting Consumer Purchase Intention. Journal of Intelligence, (11), 46-51.

Brian, T. R. (2001). The Economics of Consumer Knowledge. Journal of Consumer Research, 27(4), 397-411.

Buttle, F. A. (1998). Word of mouth: understanding and managing referral marketing. Journal of strategic marketing, 6(3), 241254.

Burton, S., Lichtenstein, D. R., Netemeyer, R. G., \& Garretson, J. A. (1998). A scale for measuring attitude toward private label products and an examination of its psychological and behavioral correlates. Journal of the academy of marketing science, 26(4), 293-306.

Cacioppo, J. T., Petty, R. E., \& Morris, K. J. (1983). Effects of need for cognition on message evaluation, recall, and persuasion. Journal of personality and social psychology, 45(4), 805-818.

Chaudhuri, A., \& Holbrook, M.B. (2001). The chain of effects from brand trust and brand affect to brand performance: the role of brand loyalty. Journal of marketing, 65(2), 81-93.

Cheung, C. M., Lee, M. K., \& Rabjohn, N. (2008). The impact of electronic word-of-mouth: The adoption of online opinions in online customer communities. Internet research, 18(3), 229247.

Davis, F. D. (1989). Perceived usefulness, perceived ease of use, and user acceptance of information technology. Management Information Systems Quarterly, 13(3), 319-340.

Datta, N., Holevo, A. S., \& Suhov, Y. M. (2005). On a sufficient condition for additivity in quantum information theory. Problems of Information Transmission, 41(2), 76-90.

Dobele, A., \& Lindgreen, A. (2010). Exploring the nature of value in the word-of-mouth referral equation for health care. Journal of Marketing Management, 27(3/4), 269-290.

Dodds, W. B., Monroe, K. B., \& Grewal, D. (1991). Effects of price, brand, and store information on buyers' product evaluations. Journal of marketing research, 28(3), 307-319.

Doll, W. J., \& Torkzadeh, G. (1988). The measurement of end-user computing satisfaction. MIS quarterly, 259-274.

Eagly, A., \& Chaiken, S. (1998). Attitude structure and function. Handbook of social psychology. Boston, MA: McGrow Hill Company.

Engel, J.F., Blackwell, R.D., \& Miniard, P.W. (1995). Consumer Behavior (8th ed). Chicago: The Dryden Press.

Fishbein, M., Jaccard, J., Davidson, A. R., Ajzen, I., \& Loken, B. (1980). Predicting and understanding family planning behaviors. In I. Ajzen, \& M. Fishbein (Eds.), Understanding attitudes and predicting social behavior.

Fishbein, M., \& Manfredo, M. J. (1992). A theory of behavior change. Influencing human behavior, 24(1), 29-50.

Gilly, M. C., Graham, J. L., Wolfinbarger, M. F., \& Yale, L. J. (1998). A dyadic study of interpersonal information search. Journal of the Academy of Marketing science, 26(2), 83-100.

Gong, S., Li, Q., Zhao, P., \& Ren, Z. W. (2018). Marketing Communication in the Digital Era: Online Advertising, Online Word of Mouth, and Mobile Game Sales. Nankai Business Review, 21(2), 28-42. 
Herr, H. W., Wartinger, D. D., Fair, W. R., \& Oettgen, H. F. (1992). Bacillus Calmette-Guerin therapy for superficial bladder cancer: a 10-year follow up. The Journal of urology, 147(4), 1020-1023.

Huang, Y., \& Zhu, S. D. (2003). Word of Mouse Marketing in the 21 st Century and Its Development Potential in China. Modernization of Management, (6), 33-36.

Lin, Y., Liu, H.L., \& Yuan, B. (2017). Consumer Response to Entrepreneur's Word of Mouth in Network Environment. China Soft Science, (01), 103-114.

Meng, Y., Wang, H., \& Wang, W. (2017). The Effect of Electronic Word of mouth on sales through fine gained sentiment analysis. Management Review, 29(1), 144-154.

Moheimani, S. O. R., Fleming, A. J., \& Behrens, S. (2003). "On the feedback structure of wideband piezoelectric shunt damping systems." IOP Smart Materials and Structures, 12, 49-56.

Netemeyer, R. G., Krishnan, B., Pullig, C., Wang, G., Yagci, M., Dean, D., Ricks, J., \& Wirth, F. (2004). Developing and validating measures of facets of customer-based brand equity. Journal of Business Research, 57(2), 209-224.

Peter, J.P., \& Olson, J.C. (1996). Understanding consumer behavior. Burr Ridge, IL: Irwin Professional Publishing.

Stauss, B. (1997). Global word of mouth: service bashing on the
Internet is a thorny issue. Marketing Management, 6(3), 28-30. Sun, C. H., \& Liu, Y. Z. (2009). The Effect of WOM on Consumers Perception of Information Usefulness. Journal of Intelligence, (10), 51-54.

Van den Berg, H., Manstead, A.S.R., Van der Pligt, J., \& Wigboldus, D.H.J. (2006). The impact of affective and cognitive focus on attitude formation. Journal of Experimental Social Psychology, 42, 373-379.

Westbrook, R. A. (1987). Product/consumption-based affective responses and post purchase processes. Journal of marketing research, 24(3), 258-270.

Wu, P., \& Li, L. (2011). An Empirical Study on the Factors Influencing Purchase Intention of Private Labels of Retailing Channels. China Business and Market, 25(5), 78-82.

Zhang, X. D., \& Zhu, M. (2011). Research on the Influence of Internet word of mouse on consumers buying behavior. Consumer Economics, (3), 15-17.

Zhang, X., \& Dong D. H. (2008). Internet Word of Mouth Strategy. Marketing Herald, (6), 61-64.

Zhang, Y. (2013). Instant Marketing Model and Strategy Realization from the Perspective of Communication - Taking WeChat Marketing as an Example. China Publishing Journal, (16), 18-20. 